\title{
More Aboriginal mothers are attending their first antenatal visit before 14 or 20 weeks gestation in NSW
}

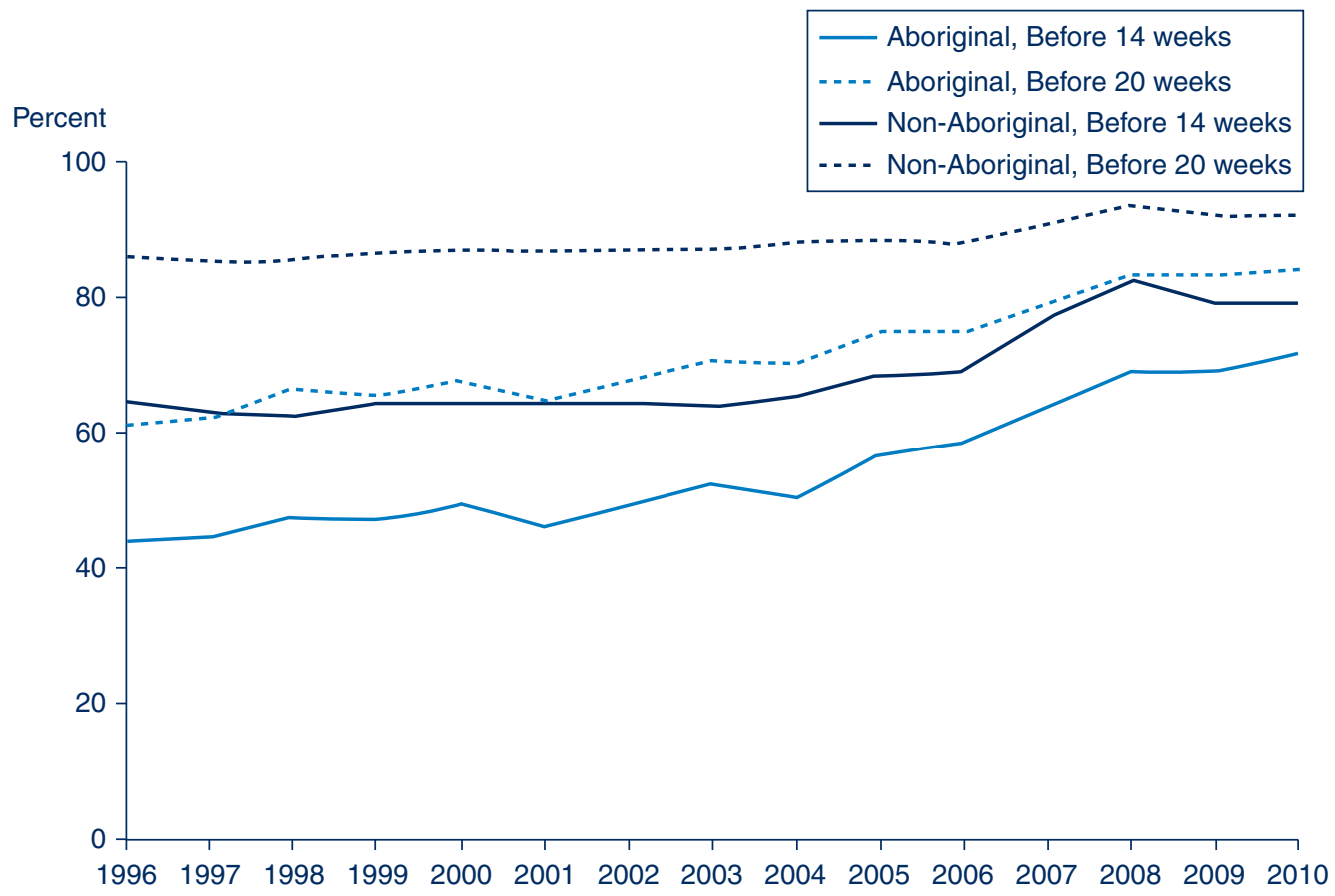

Over the period 1996 to 2010 in NSW, the proportion of Aboriginal mothers who attended their first antenatal visit before 14 weeks gestation increased from $43.8 \%$ to $71.3 \%$. However, the proportion is still below that recorded for nonAboriginal mothers at $79.6 \%$ in 2010 .

The purpose of antenatal visits is to monitor the health of the mother and baby, provide advice to promote the health of the mother and baby, and identify antenatal complications so that appropriate intervention can be provided at the earliest time. Potential complications include antepartum haemorrhage, placenta praevia, placenta abruptio, prolonged rupture of membranes, gestational diabetes, threatened preterm labour, hypertensive disease of pregnancy and rhesus isoimmunisation, cervical incompetence, polyhydramnios, oligohydramnios, chorioamnionitis, threatened miscarriage, and problems secondary to multiple pregnancy.

Sources: NSW Perinatal Data Collection (HOIST). Centre for Epidemiology and Evidence, NSW Ministry of Health.

Note: Antenatal care should commence as early as possible in pregnancy to ensure the best outcomes for the mother and the baby. All deliveries in New South Wales (NSW) were included. Due to under-reporting of Aboriginality to the Perinatal Data Collection, the true numbers are likely to be about 50\% higher than shown. The level of under-reporting varies between Local Health Districts.

Further information and data on a range of public health indicators is available from the Health Statistics NSW website at: www.healthstats.nsw.gov.au. 